\title{
The Impact of Self-Regulated Strategy Development on Vocabulary Learning among English Language Learners
}

\author{
Hamidreza Fatemipour (Corresponding author) \\ Assistant Professor, ELT Department, College of Persian Literature and Foreign Languages, Roudehen Branch \\ Islamic Azad University, Roudehen, Iran; Email: hamidfatemipour@yahoo.com

\section{Mona Najafgholikhan} \\ M. A. in ELT, ELT Department, College of Persian Literature and Foreign Languages, Roudehen Branch \\ Islamic Azad University, Roudehen, Iran; Email: Mona.najafgholikhan@gmail.com
}

Doi:10.5901/mjss.2015.v6n5s2p249

\section{Abstract}

\begin{abstract}
The purpose of the study was to determine the impact of self-regulated strategy development (SRSD) on vocabulary learning of students' English as a foreign language (EFL), and find the relationship between male and female participants with regard to the effect of SRSD on their vocabulary learning. To achieve this goal, 60 homogeneous intermediate EFL learners (30 male and 30 female) were randomly assigned to two groups of 30, a control group who received the mainstream instruction for intermediate learners and an experimental group who received additional training using self-regulated strategy development in their vocabulary instruction. The treatment consisted of five vocabulary learning strategies (using a monolingual dictionary, using new words in sentences, guessing meaning from the context, word part analysis and repetition) which were reinforced through five steps of SRSD, i.e., discuss it, model it, make it your own, support it and independent performance. A quasiexperimental design was adopted to collect the data. The results indicated that self-regulated strategy development can have a significantly positive impact on the vocabulary learning of Iranian intermediate EFL learners and this impact does not differ among male and female EFL learners. Based on the findings of the study, it was suggested that self-regulated strategy development is used in English language classes in order to teach vocabulary. Further educational implications of the study have been elaborated in the paper.
\end{abstract}

Keywords: self-regulated strategy development, vocabulary learning, vocabulary learning strategies, EFL

\section{Introduction}

Vocabulary learning plays a crucial role in any language learning context helping learners to better express their feelings and ideas to their interlocutor through communication. Research has proved that large vocabulary knowledge is necessary to function in English, somewhat 8000-9000 words to be able to read and approximately 5000-6000 words for oral discourse (Schmitt, 2008). Many learners find it difficult to memorize all this vocabulary and may complain about the problems of remembering the new words later on. EFL teachers try to employ various methods to teach vocabulary in order to achieve the best outcome. On the other hand, research has shown that self-regulated strategy development (SRSD) has a significant effect on the improvement of the quality of learners' writing (Graham, 2006; Graham \& Harris, 2003; Graham \& Perrin, 2006).

In a class where SRSD instruction is applied, learners are provided with opportunities to develop the attributions for effort and the application of workable strategies, the knowledge of various genres, self-efficacy, and a great deal of involvement (Harris, 1985; Harris \& Graham, 1992), which may in turn be beneficial in their academic outcome. This suggests that by employing an SRSD model in teaching EFL learners new vocabulary, better results can be expected.

\subsection{What is Self-Regulation?}

Self-regulation refers to "thoughts, feelings and actions that are planned and adapted to the attainment of personal goals" (Zimmerman, 2004, p. 4) Self-regulation is a wide-ranging notion which includes a number of inter-dependent features. It consists of affective capacities, (e.g., moods, feelings and emotions), and cognitive capacities, (e.g., beliefs, perceptions and knowledge). Self-regulation is considered as a dynamic concept. It means that the activities and thinking processes 
that students are involved in are not fixed and change based on the particular traits that students have. For instance, one thing which is taken into consideration in self-regulation classes is focusing on how learners actively manage their feeling and motivation to learn. Learners can develop their self-regulation through practice (Duckworth, Akerman, MacGregor, Salter, \& Varhaus, 2009).

\subsection{What is Self-Regulated Strategy Development?}

Self-Regulated Strategy Development (SRSD) is a flexible instructional model that helps students explicitly learn how to plan, draft, and revise strategies that are utilized by skillful language learners (Graham \& Harris, 2005). SRSD is an approach an extra component that is self-regulation to strategy instruction. It motivates the learners to monitor, evaluate and modify their language production which in turn strengthens self-regulation skills and autonomous learning.

Graham and Harris (2005) depict a process to SRSD instruction which contains five steps. By following the instructional sequence described below, teachers can help their students learn the strategy and use it automatically. These steps include: discuss it, model it, make it your own, support it, and independent performance. Each step is described thoroughly in the following subsections.

\subsubsection{Step 1: Discuss It}

Prepare the stage. Let the students know when and how they might use a strategy to do specific learning tasks. Explain the advantages of becoming a more proficient, flexible learner. Talk about the negative effects of having unpleasant selftalk or negative beliefs the learners may have. Teach students how to measure their progress in utilizing the strategy and its effect on their learning.

\subsubsection{Step 2: Model It}

Model the strategy through using think-aloud, self-talk, and self-instruction. Then explain how the strategy might be customized in order to be more effective and efficient for each learner. Students should be asked to think of their special purposes. Modeling the strategy should be repeated for different sample texts.

\subsubsection{Step 3: Make It Your Own}

Strategies are consisted of different steps just like a checklist. When the steps are followed in a sentence, in the context of a puzzle, or a crossword, it becomes easier for the learners to remember them. Graham and Harris (2005) believe that the steps can be labeled in a way that the learners can remember them. By renaming the steps, the students make a meaningful connection between what they do and the names which represent them.

\subsubsection{Step 4: Support It}

In order to support a strategy, it should be used regularly and in as many ways as possible. The teachers as well as the learners can support the process of utilizing the strategy through offering direct help, prompts, fruitful feedback, and reinforcement. When a new kind of application of the strategy is introduced, it is good to model the strategy once again. The ultimate goal is that learners make their own purposes, observe their own use of the strategy, and have their independent self-statements.

\subsubsection{Step 5: Independent Performance}

Learners begin to use the strategy individually while working on different tasks. In the case of the graphic organizers, learners will be able to draw them without help.

\subsection{Vocabulary Learning Strategies}

Vocabulary learning strategies are defined according to the definition of learning strategies. Nation (2001) asserts that "vocabulary learning strategies are a part of language learning strategies, which in turn are a part of general learning strategies" (p. 217). Regarding the definition of learning strategies, offered by O'Malley and Chamot's (1990), Schmitt 
(1997) claims that learning is "the process by which information is obtained, stored, retrieved and used. Therefore, vocabulary learning strategies could be any strategies which affect this broadly defined process" (p. 203). Instead of providing a precise definition of vocabulary learning strategies, Nation (2001) has listed their characteristics. Nation (2001) states that "a strategy must involve choice (i.e., there should be several strategies to choose from), be complex (i.e., there should be several steps to learn), require knowledge and benefit from training, and increase the efficiency of vocabulary learning and vocabulary use" (p. 217).

Traditionally, vocabulary was taught in isolation with a word list which contained English definitions, L1 meanings, example sentences, synonyms or antonyms. Nevertheless, traditional ways of vocabulary teaching have been criticized (Yuan \& Lin, 2001). Many scholars have suggested various important vocabulary teaching techniques or instructional strategies such as teaching prefixes, suffixes and roots, teaching collocations, polysemous words, words in context, guessing words from context, teaching culture, translation, songs, and dictionary skills to help students learn vocabulary (Wu, 2002).

Schmitt (1997) suggested a list of vocabulary learning strategies and classified them according to a descriptive system. First, he referred to Oxford's (1990) classification scheme and selected the four mentioned strategy groups (Social, Memory, Cognitive, and Metacognitive) which appeared to be suitable for illustrating different Vocabulary Learning Strategies (VLS). Social strategies are those strategies which students use in order to interact with other people to learn better. Memory strategies consist of those strategies which help students to connect new materials with present knowledge system. Skills which need "manipulation or transformation of the target language by the learner" fall into the cognitive strategies (Oxford, 1990, p. 43). Finally, metacognitive strategies "involve a conscious overview of the learning process and making decisions about planning, monitoring, or evaluating the best way to study" (Schmitt, 1997, p. 205).

Since Oxford's (1990) system generally covers Language Learning Strategies (LLS) and thus seems not to deal with certain specific strategies applied in vocabulary learning, Schmitt designed a new category for those strategies learners use when they find the meaning of a new word without the help of other individuals, namely "Determination Strategies". In addition, Cook and Mayer (1983) made a helpful distinction in this regard, and Nation's (1990) system was incorporated into Schmitt's (1997) classification scheme. That is, regarding the process which is involved in vocabulary learning, strategies may be divided into two categories: a) those for finding the meaning of the new word and; $b$ ) those for associating a word when the learner faces it.

Discovery strategies consist of many determination and social strategies. A learner may obtain the meaning of a new word through guessing from the context, guessing from his mother tongue cognate, using reference materials (e.g., a dictionary), or asking others (e.g., their teacher or classmates). There is a natural sense that almost all of the strategies uesd to discovery activities could be applied as association strategies in the later stage of vocabulary learning (Schmitt, 1997). There are some strategies under the above-mentioned categories such as: a) using monolingual dictionaries; $b$ ) guessing meaning from the context; c) studying new words over and over again; d) connecting the word to its synonyms and antonyms; e) using new words in sentences; f) using English language media; g) taking notes or highlighting; h) studying the sound of a word; i) making lists of new words; j) writing paragraphs utilizing new words; $k$ ) studying the word with classmates; I) asking classmates for the word meaning; m) checking for L1 cognate; n) using physical action when learning a word; o) talking with native speakers; p) asking the teacher to check the given definition (Hamzah, Kafipour , \& Abdullah, 2009).

Another classification of vocabulary learning strategies has been suggested by O'Malley and Chamot (1990). They divide vocabulary learning strategies into three groups: cognitive, metacognitive and social/affective. Cognitive strategies are referred as learning steps taken by the learners to transform new material, for example, inference, guessing from the contexts and relating new concepts to the old ones stored in the learners' memories. Metacognitive strategies manage the learners' endowers to carry out the learning task. Social/affective strategies encompass interaction with other students or controlling the learners' feelings on the process of language learning.

$\mathrm{Gu}$ and Johnson (1996) divide vocabulary learning strategies into two categories: cognitive and metacognitive. Cognitive strategies consist of memory, classification, guessing, dictionary, note-taking, and activation strategies. While metacognitive strategies include plan-making, self-evaluating, self-checking, and selectively distributing attention strategies.

According to Nation (2001), vocabulary learning strategies are divided into three general categories: planning, sources and process. Planning consists of selecting words, selecting the aspects of word knowledge, selecting appropriate strategies, and planning repetition. Sources consists of analyzing the words, using word part, learning from word cards, using context, looking up a word in a dictionary, referring to a source in both first and second languages. Process consists of noticing, retrieving, and generating. 


\subsection{Related Studies on SRSD and Vocabulary Learning}

Several studies have shown that SRSD leads to significant improvements in writing knowledge, writing quality, writing approach, self-regulation skills, and motivation. Santangelo, Harris and Graham (2008) used the SRSD model to teach writing strategies to elementary, middle, and high school students. The results of their study showed that SRSD model had a significant positive effect on teaching writing skill. In a different study, Graham, Harris and Mason (2005) tested the effect of SRSD on the writing performance, knowledge, and self-efficacy of struggling young writers and discovered that not only the students wrote longer, more complete, and qualitatively better papers, but also SRSD instruction had increased their knowledge about writing. Self-regulation strategy development has proved to be effective with writing proficiency; however, other skills can also be altered through SRSD instruction. In a different context, Case, Harris and Graham (1992) used SRSD instruction to improve the mathematical problem-solving skills of learners who had learning disabilities and revealed that the students' total performance on mixed sets of addition and subtraction word problems improved.

Regarding vocabulary learning, the only study conducted by Araya, Pena, Rodriguez, Spate and Vergara (2013) revealed that providing self-regulatory training to students and making them aware of it, can be considered as the foundation for general learning and, specifically, in terms of vocabulary knowledge.

Haji Hasan Hamedi (2013) studied the relationship between self-efficacy and self-regulation in vocabulary learning of Iranian EFL learners. She concluded that self-efficacy, and self-regulated strategies are two important concepts which can speed up the process of vocabulary learning and help EFL teachers and learners. In another study by Heidari, Izadi and Vahed Ahmadian (2012), the relationship between Iranian EFL Learners' self-efficacy beliefs with the use of vocabulary learning strategies was investigated. They reported that a significantly positive relationship was observed between self-efficacy and the use of vocabulary learning strategies. They maintained that learners with high self-efficacy used vocabulary strategies more than the ones with low self-efficacy. However, self-regulated strategy development seems to be unrecognized by Iranian researchers as no study to date has been conducted on SRSD in Iran. Therefore, the impact of SRSD on vocabulary learning, or on any other skill, has not been studied in Iran prior to the current research study.

\section{Method}

The main purpose of this study was to investigate the effect of self-regulated strategy development on vocabulary learning of Iranian EFL learners. Concerning the objectives of the study, the following research questions were propounded:

1. Does self-regulated strategy development affect vocabulary learning of Iranian EFL learners?

2. Is there a statistically significant difference between male and female participants with regard to the effect of SRSD on their vocabulary learning?

\subsection{Participants}

The participants of the study consisted of 60 intermediate Iranian EFL learners. They were divided into experimental and control groups. Each group contained 30 homogeneous learners, including 15 male and 15 female participants. The participants had been given the Cambridge Preliminary English Test (PET) prior to the experiments and those who had scored one standard deviation above and below the mean were chosen to participate in this study. Their age range was between 18 and 54; therefore, they were adult learners of English language.

\subsection{Instruments}

In order to measure the participants' vocabulary learning, a vocabulary test was designed by the researchers and administered as a measure of vocabulary knowledge. The test consisted of 60 items from the new vocabulary section of the book entitled, "Total English for Intermediate students", which was the material for general English instruction in the institute where the study was taking place. It was an achievement test, testing the participant's knowledge and understanding of the new vocabulary in units one and two of the Total English course book for intermediate students.

The test was read and approved by two experts on ELT and testing for content validity. The test was administered as a pretest and a posttest to examine the effects of integrating a self-regulated strategy development approach into regular English courses. The test was initially piloted on a group of 10 intermediate students after which modifications 
were made to the test and it was then finalized. The reliability of the test has been presented in Table 1 . As it is shown, KR-21 reliability indices for the pretest and posttest of vocabulary were .77 and .90 respectively.

Table 1. KR-21 Reliability Indices

\begin{tabular}{lcc|cc}
\hline & $\mathrm{N}$ & Mean & Variance & KR-21 \\
\hline Pretest & 60 & 31.95 & 15.608 & .77 \\
Posttest & 60 & 44.60 & 40.515 & .90 \\
\hline
\end{tabular}

\subsection{Procedure of the Study}

The first step in this study included the selection of the participants. In order to do this, approximately 80 EFL learners were tested for their general English ability, those scoring one standard deviation below and above the mean of the scores were selected as a homogeneous group, containing an equal number of men and women. The participants were assigned into two groups of 30 , one as the experimental group and the other as the control group. The two groups of participants were met on a regular basis. Both the experimental and the control groups received the same training in general English. Only the experimental group received the treatment designed using self-regulated strategy development.

The semester lasted for 20 sessions of ELT instruction in the institute where the study was carried out. Each session lasted one and half hours. The treatment was given in 10 sessions. A total of five vocabulary learning strategies were taught and practiced through SRSD during the treatment sessions. Approximately one new strategy was taught and practiced every two sessions.

The vocabulary learning strategies that were taught included using a monolingual dictionary, using new words in sentences, guessing meaning from context, word part analysis and repetition. The first session was used to present the strategy through SRSD instruction. In the second session, more practice was encouraged and the participants were asked to use the strategy they had learnt recently when learning the new vocabulary taught on that day. Each strategy was first discussed by the teacher and the students. Benefits of using the strategy were talked about and students were motivated to learn and use the strategy. In the second step, the strategy was modeled by the teacher a number of times giving different examples. The students were then asked to make it their own, i.e., customize it according to their habits and beliefs. The fourth and fifth steps of SRSD instruction were practiced on the second session of instruction of the strategy. The students were asked to use the strategy as much as possible for the new words taught on that session. After a few sessions, the students learned to perform the strategy independently.

A vocabulary test was given to the learners before and after the treatment. The scores were analyzed using the SPSS software in order to indicate the effect of employing a self-regulated strategy development model on the vocabulary learning of the participants. Then, conclusions were drawn from the results of the data analysis.

\subsection{Design of the Study}

A quasi-experimental design was proposed to test the hypotheses of this study. Therefore, the researchers deliberately manipulated one variable (through SRSD treatment) in order to determine its effect on the other variable (vocabulary learning of Iranian EFL learners) as the dependent variable. Since a quasi-experimental design was adopted, no random sampling took place. The researchers performed convenient sampling in order to form two homogeneous groups. In the present study, two groups of homogenous learners were assigned, one as the experimental group and the other as the control group. Both groups were met on a regular basis (three times a week, for 20 sessions, with each session lasting one and a half hours). Only the experimental group received the treatment in self-regulated strategy development. A pretest and a posttest were given to both groups, and the differences were studied through data analysis. A two-way ANOVA was then performed to determine the effect of SRSD on the vocabulary learning of the EFL learners.

\section{Results and Discussion}

This study aimed at investigating the effect of self-regulated strategy development (SRSD) on vocabulary learning of male and female Iranian EFL learners. The two-way analysis of variances was run to probe the research questions posed in this study. This parametric statistical test is based on two main assumption of homogeneity of variances and normality. The former will be discussed when presenting the main results. The assumption of normality was met. As displayed in Table 2, the ratios of skewness and kurtosis over their respective standard errors were within the ranges of $+/-1.96$. 
Table 2. Testing Normality Assumptions

\begin{tabular}{llc|cc|c|ccc}
\hline \multirow{2}{*}{ Group } & & $\mathrm{N}$ & \multicolumn{3}{|c|}{ Skewness } & \multicolumn{3}{c}{ Kurtosis } \\
\cline { 3 - 8 } & & Statistic & Statistic & Std. Error & Ratio & Statistic & Std. Error & Ratio \\
\hline \multirow{2}{*}{ Experimental } & Pretest & 30 & .223 & .427 & .522 & -.372 & .833 & -.44 \\
& Posttest & 30 & .028 & .427 & .065 & -.574 & .833 & -.68 \\
\hline \multirow{2}{*}{ Control } & Pretest & 30 & .316 & .427 & .740 & -.289 & .833 & -.34 \\
& Posttest & 30 & .319 & .427 & .747 & .051 & .833 & .061 \\
\hline
\end{tabular}

\subsection{Pretest of Vocabulary}

A two-way ANOVA was run to compare the male and female experimental and control groups' means on the pretest of vocabulary in order to prove that they were homogenous in terms of their vocabulary knowledge prior to the main study. Before discussing the two-way ANOVA results, it should be mentioned that the groups enjoyed homogenous variances on the pretest of vocabulary. As displayed in Table 3, the Levene's F-value of .913 was not significant $(P>.05)$.

Table 3. Levene's Test of Equality of Error Variances

\begin{tabular}{ccc|c}
\hline$F$ & df1 & df2 & Sig. \\
\hline .913 & 3 & 56 & .441 \\
\hline
\end{tabular}

As displayed in Table 4, the experimental $(M=32.50, S E=.72)$ and control $(M=31.40, S E=.72)$ groups showed almost the same means on pretest of vocabulary.

Table 4. Descriptive Statistics, Pretest of Vocabulary by Groups

\begin{tabular}{lcc|cc}
\hline \multirow{2}{*}{ Group } & \multirow{2}{*}{ Mean } & \multirow{2}{*}{ Std. Error } & \multicolumn{2}{|c}{ 95\% Confidence Interval } \\
\cline { 4 - 5 } & & & Lower Bound & Upper Bound \\
\hline Experimental & 32.500 & .726 & 31.046 & 33.954 \\
Control & 31.400 & .726 & 29.946 & 32.854 \\
\hline
\end{tabular}

Based on the results displayed in Table $5,\left(F(1,56)=1.14, P>.05 ; \eta^{2}=.020\right.$ it represents a weak effect size $)$ it can be concluded that there was not any significant difference between experimental and control groups' means on the pretest of vocabulary.

Table 5. Tests of Between-Subjects Effects, Pretest of Vocabulary by Groups

\begin{tabular}{lcr|cc|lc}
\hline Source & Type III Sum of Squares & Df & Mean Square & $F$ & Sig. & Partial Eta Squared \\
\hline Group & 18.150 & 1 & 18.150 & 1.149 & .288 & .020 \\
\hline Gender & 6.017 & 1 & 6.017 & .381 & .540 & .007 \\
Group * Gender & 12.150 & 1 & 12.150 & .769 & .384 & .014 \\
Error & 884.533 & 56 & 15.795 & & & \\
\hline Total & 62169.000 & 60 & & & & \\
\hline
\end{tabular}

As displayed in Table 6 , the male $(M=32.26, \mathrm{SE}=.72)$ and female $(\mathrm{M}=31.63$, SE $=.72)$ subjects showed almost the same means on pretest of vocabulary.

Table 6. Descriptive Statistics, Pretest of Vocabulary by Gender

\begin{tabular}{lcc|cc}
\hline \multirow{2}{*}{ Group } & \multirow{2}{*}{ Mean } & \multirow{2}{*}{ Std. Error } & \multicolumn{2}{|c}{ 95\% Confidence Interval } \\
\cline { 4 - 5 } & & & Lower Bound & Upper Bound \\
\hline Male & 32.267 & .726 & 30.813 & 33.720 \\
Female & 31.633 & .726 & 30.180 & 33.087 \\
\hline
\end{tabular}


As displayed in Table 7, and Figure 1, the means for the male and female experimental and control groups on the pretest of vocabulary did not show any significant interaction.

Table 7. Interaction between Group Gender, Pretest of Vocabulary

\begin{tabular}{lll|cc|c}
\hline \multirow{2}{*}{ Group } & \multirow{2}{*}{ Gender } & \multirow{2}{*}{ Mean } & \multirow{2}{*}{ Std. Error } & \multicolumn{2}{c}{ 95\% Confidence Interval } \\
\cline { 5 - 6 } Experimental & Male & 33.267 & 1.026 & Lower Bound & Upper Bound \\
& Female & 31.733 & 1.026 & 29.671 & 35.322 \\
\multirow{2}{*}{ Control } & Male & 31.267 & 1.026 & 29.211 & 33.789 \\
& Female & 31.533 & 1.026 & 29.478 & 33.322 \\
& & & & & 33.589 \\
\hline
\end{tabular}

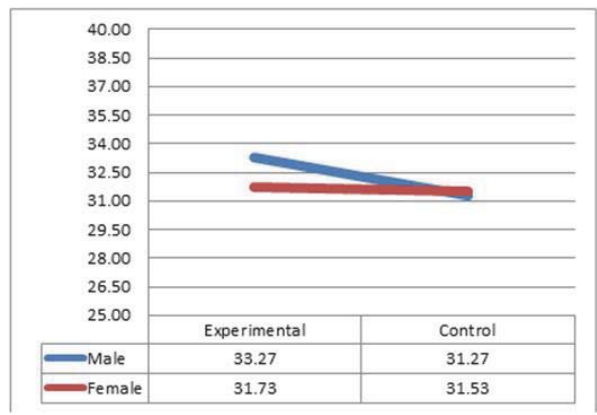

Figure 1. Pretest of Vocabulary Groups by Gender

\subsection{Research Questions}

Does self-regulated strategy development affect vocabulary learning of Iranian EFL learners? Is there statistically difference between male and female participants with regard to the effect of SRSD on their vocabulary learning? A twoway ANOVA was run to compare the male and female experimental and control groups' means on the posttest of vocabulary in order to probe research questions posed in this study. Before discussing the two-way ANOVA results, it should be mentioned that the groups enjoyed homogenous variances on the pretest of vocabulary. As displayed in Table 8, the Levene's F-value of 2.12 was not significant $(P>.05)$.

Table 8. Levene's Test of Equality of Error Variances

\begin{tabular}{ccc|c}
\hline$F$ & df1 & df2 & Sig. \\
\hline 2.126 & 3 & 56 & .107 \\
\hline
\end{tabular}

As displayed in Table 9, the experimental $(M=49.30, S E=.76)$ outperformed the control $(M=39.90, S E=.79)$ group on posttest of vocabulary.

Table 9. Descriptive Statistics, Posttest of Vocabulary by Groups

\begin{tabular}{lcc|cc}
\hline \multirow{2}{*}{ Group } & \multirow{2}{*}{ Mean } & \multirow{2}{*}{ Std. Error } & \multicolumn{2}{|c}{ 95\% Confidence Interval } \\
\cline { 4 - 5 } & & & Lower Bound & Upper Bound \\
\hline Experimental & 49.300 & .796 & 47.706 & 50.894 \\
Control & 39.900 & .796 & 38.306 & 41.494 \\
\hline
\end{tabular}

Based on the results displayed in Table $10,\left(F(1,56)=69.76, P<.05 ; \eta^{2}=.55\right.$ it represents a large effect size), it can be concluded that there was a significant difference between experimental and control groups' means on the posttest of vocabulary. Thus the first null-hypothesis was rejected. Having receiving SRSD, the experimental group outperformed the 
control group on the posttest of vocabulary.

Table 10. Tests of Between-Subjects Effects, Posttest of Vocabulary by Groups

\begin{tabular}{|c|c|c|c|c|c|c|}
\hline Source & Type III Sum of Squares & $\mathrm{Df}$ & Mean Square & $\mathrm{F}$ & Sig. & Partial Eta Squared \\
\hline Group & 1325 & 1 & 1325 & 69.767 & .000 & .555 \\
\hline Gender & 1.067 & 1 & 1.067 & .056 & 814 & .001 \\
\hline Group * Gender & .067 & 1 & .067 & .004 & 953 & .000 \\
\hline Error & 1063 & 56 & 18 & & & \\
\hline Total & 121740 & 60 & & & & \\
\hline
\end{tabular}

As displayed in Table 11, the male $(M=44.73, \mathrm{SE}=.79)$ and female $(\mathrm{M}=44.46, \mathrm{SE}=.79)$ subjects showed almost the same means on posttest of vocabulary.

Table 11. Descriptive Statistics, Posttest of Vocabulary by Gender

\begin{tabular}{lcc|cc}
\hline \multirow{2}{*}{ Group } & \multirow{2}{*}{ Mean } & \multirow{2}{*}{ Std. Error } & \multicolumn{2}{|c}{ 95\% Confidence Interval } \\
\cline { 4 - 5 } & & & Lower Bound & Upper Bound \\
\hline Male & 44.733 & .796 & 43.139 & 46.327 \\
Female & 44.467 & .796 & 42.873 & 46.061 \\
\hline
\end{tabular}

Based on the results displayed in Table $9,\left(F(1,56)=.056, P>.05 ; \eta^{2}=.001\right.$ it represents a weak effect size), it can be concluded that there was not any significant difference between male and female subjects' means on the posttest of vocabulary. Thus the second null-hypothesis was not rejected.

Finally there were not any significant interaction between the groups and gender on the posttest of reading comprehension $\left(F(1,56)=.004, P>.05 ; \eta^{2}=.000\right.$ it represents a weak effect size) (Table 5). As displayed in Table 12 and Figure 2, the means for the male and female experimental and control groups on the posttest of vocabulary did not show any significant interaction.

Table 12. Interaction between Group * Gender, Posttest of Vocabulary

\begin{tabular}{lcc|cc|c}
\hline \multirow{2}{*}{ Group } & \multirow{2}{*}{ Gender } & \multirow{2}{*}{ Mean } & \multirow{2}{*}{ Std. Error } & \multicolumn{2}{c}{ 95\% Confidence Interval } \\
\cline { 5 - 6 } & & & & Lower Bound & Upper Bound \\
\hline \multirow{2}{*}{ Experimental } & Male & 49.400 & 1.125 & 47.146 & 51.654 \\
& Female & 49.200 & 1.125 & 46.946 & 51.454 \\
\hline \multirow{2}{*}{ Control } & Male & 40.067 & 1.125 & 37.812 & 42.321 \\
& Female & 39.733 & 1.125 & 37.479 & 41.988 \\
\hline
\end{tabular}

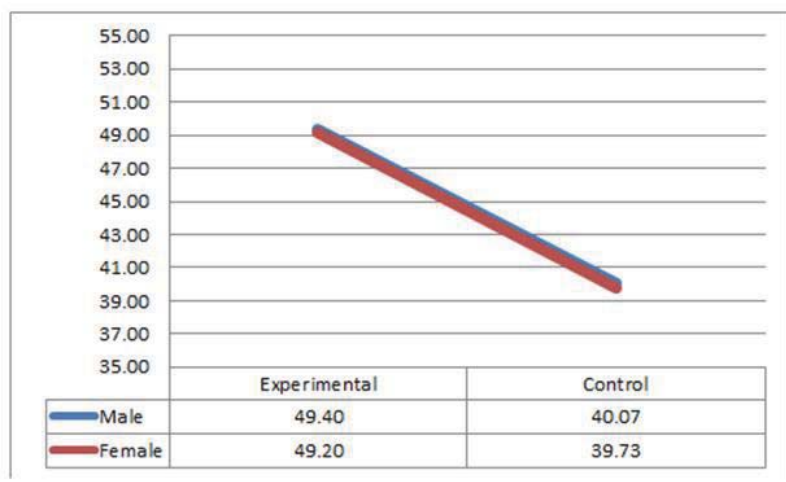

Figure 2. Posttest of Vocabulary Groups by Gender 


\section{Conclusion}

The findings of this study revealed that self-regulated strategy development has a significantly positive impact on the vocabulary learning of Iranian intermediate EFL learners. This aligns with the findings of a similar study by Araya et al. (2013) in which they concluded that providing self-regulatory training to students and making them aware of it, can be considered as the foundation for general learning, specifically, in terms of vocabulary knowledge.

However, it challenges the conclusion made by Santangelo et al. (2008) who stated that the SRSD model was well suited for writing instruction only. As the first study to investigate the effect of SRSD on vocabulary learning, the present research has proven that SRSD can be beneficial in teaching vocabulary as well. Nevertheless, in his study, Mitzumoto (2013) declared that it would be reasonable to assume that the enhanced self-efficacy through a self-regulated learning approach may lead to a gain in vocabulary knowledge.

It was also revealed that self-regulated strategy development has the same impact on the vocabulary learning of male and female EFL learners. This emphasizes the importance of SRSD in the ELT classroom, regardless of the students' gender. Several pedagogical implications emerged from the results of the present study.

To start with, self-regulated strategy development can be adopted in the English language classes especially in ELT institutes, as an accelerator to teach vocabulary learning strategies as well as writing strategies to the learners. The vocabulary taught through the strategies reinforced by the self-regulated strategy development model can make a deeper impression on the learners and therefore, and are less likely to be forgotten in a short notice.

As there was no statistically significant difference between male and female participants in the impact that selfregulated strategy development had on their vocabulary learning, it is recommended that self-regulated strategy development is used in both only-girls and only-boys EFL classes as well as coeducational ones.

SRSD instruction can be employed at universities where English is being taught either in general English courses or for ESP courses, where the students have to focus on vocabulary learning.

As the self-regulated strategy development is not currently used widely in EFL classes, it is recommended that teachers become familiar with the term and its positive outcome. Experienced teachers can become familiar with SRSD instruction through in-service training sessions in order to feel more open to adopt it in their classes.

EFL institutions and academic centers focusing on EFL education can also incorporate SRSD instruction into their syllabus and create an opportunity for improvement in vocabulary learning and teaching for both learners and teachers. SRSD instruction can also be presented and practiced at universities, especially for TEFL students who wish to become ELT teachers in future.

Since the study was limited to vocabulary learning, further investigation can shed light on the impact of SRSD instruction on the learning of other English language skills and components where applicable.

\section{References}

Araya, D., Pena, R., Rodriguez, N., Spate, S., \& Vergara, K. (2013). Learning strategies and self-regulationin vocabulary acquisition: A research project about EFL learners' study experience and achievement. [Online] Available: http://www.repositorio. uchile.cl/handle/2250/112733 (March 20, 2015)

Case, L. P., Harris, K. R., \& Graham, S. (1992). Improving the Mathematical Problem-Solving Skills of Students with Learning Disabilities: Self-Regulated Strategy Development. The journal of special education, 26(1), 1-19.

Cook, L. K.,\&Mayer, R. E. (1983). Reading strategies training for meaningful learning from prose. In M. Pressley and J. Levin (Eds.), Cognitive Strategy Research (pp. 87-131). New York: Springer Verlag.

Duckworth, K., Akerman, R., MacGregor, A., Salter, E., \& Varhaus, J. (2009). Self-regulated learning: A literature review. London: Centre for Research on the Wider Benefits of Learning Institute of Education, University of London.

Graham, S., \& Harris, K. (2003). Students with learning disabilities and the process of writing: A meta-analysis of SRSD studies. In A. Swanson, K. Harris, \& S. Graham (Eds.), Handbook of learning disabilities (pp. 323-344). New York: Guilford Press.

Graham, S., \& Harris, K. (2005). Writing better: Effective strategies for teaching students with learning difficulties. Baltimore: Paul H. Brookes.

Graham, S., Harris, K. R., \& Mason, L. (2005). Improving the writing performance, knowledge, and motivation of struggling young writers: The effects of self-regulated strategy development. Contemporary Educational Psychology, 30, 207-241.

Graham, S. (2006). Strategy instruction and the teaching of writing. In C. MacArthur, S. Graham, \& J. Fitzgerald (Eds.), Handbook of writing research (pp. 187-207). New York: Guilford Press.

Graham, S., \& Perrin, D. (2006). Improving the writing ability of adolescent students: A cumulative meta-analysis. In A. Henriquez (Ed.), Annual report on adolescent literacy(pp. 448-456). New York: Carnegie Foundation.

Gu, Y. Q., \& Johnson, R. K. (1996). Vocabulary learning strategies and language learning outcomes. Language Learning, 46(4), 643679. 
Haji Hassan Hamedi, S. (2013). The Relationship between Self-Efficacy and Self-Regulation in Vocabulary Acquisition of Iranian EFL Learners. Journal of Academic and Applied Studies, 3(1), 20-31.

Hamzah, S., Kafipour, R., \& Abdullah, S. (2009). Vocabulary learning strategies of Iranian undegraduate EFL students and its relation to their vocabulary size. European journal of social sciences, 11(1), 39-47.

Harris, K. (1985). Conceptual, methodological, and clinical issues in cognitive-behavioral assessment. Journal of abnormal child psychology, 13, 373-390.

Harris, K., \& Graham, S. (1992). Self-regulated strategy development: A part of the writing process. In K. Harris, \& J. Guthrie (Eds.), Promoting academic competence and literacy at school (pp. 277-309). New York: Academic press.

Heidari, F., Izadi, M., \& Vahed Ahmadian, M. (2012). The Relationship between Iranian EFL Learners' Self-efficacy Beliefs and Use of Vocabulary Learning Strategies. English Language Teaching, 5(2), 174-182.

Mitzumoto, A. (2013). Enhancing self-efficacy in vocabulary learning: a self-regulated learning approach. Vocabulary learning and instruction, 2(1), 15-24.

Nation, I. S. P. (1990). Teaching and learning vocabulary. NewYork: Newbury House/Harper \& Row.

Nation, I. (2001). Learning vocabulary in another language. Cambridge: Cambridge University Press.

O'Malley, J. M., \& Chamot, A. U. (1990). Learning Strategies in Second Language Acquisition. Cambridge: Cambridge University Press.

Oxford, R. (1990). Language Learning Strategies: What Every Teacher Should Know. NY: Newbury House.

Santangelo, T., Harris, K., \& Graham, S. (2008). Using self-regulated strategydevelopment to support students who have "Trubol giting thangs into werds".Remedial and special education, 29(2), 78-89.

Schmitt, N. (1997). Vocabulary learning strategies. In N. Schmitt \& M. McCarthy (Eds.), Vocabulary: Description, acquisition and pedagogy (pp. 199-227). Cambridge: Cambridge University Press.

Schmitt, N. (2008). Review article: Instructed second language vocabulary learning. Language teaching research, 12(3), 329-363.

Wu, H.Y. (2002). Teaching techniques that keep university students interested in English learning. The $11^{\text {th }}$ international Symposium on English teaching, the $4^{\text {th }}$ Pan-Asian Conference (pp. 565-571). Taipei: Crane Publishing Co.

Yuan, H.C., \& Lin, C.Y. (2001). Collocation: A case study of Ming Chuan University students. The proceedings of the $18^{\text {th }}$ conference on English teaching and learning in the ROC (pp. 407-422). Taipei: Crane Publishing Co.

Zimmerman, B. J. (2004). Sociocultural influence and students' development of academic self-regulation: A social-cognitive perspective. In D. M. Mclnerny, S. Van Etten, D. M. Mclnerny, \& S. Van Etten (Eds.), Big theories revisted (pp. 139-164). Greenwhich, CT: Information Age. 